\title{
Ethological analysis of predator avoidance by the paradise fish (Macropodus opercularis L.): II. Key stimuli in avoidance learning
}

\author{
V. CSÁNYI \\ L. Eötvös University of Budapest, Hungary
}

\begin{abstract}
The possible role of eyespot patterns in predator recognition by paradise fish was examined using a passive avoidance conditioning technique with various dummies or live goldfish. It was found that a low-intensity shock, although clearly uncomfortable, elicited exploratory behavior in the fish and that observable learning did not occur. However, if the paradise fish was shocked in the presence of a live goldfish or various fish dummies, exploration diminished and avoidance learning was detected. This was characterized by a considerable increase in latency to enter the shocked compartment. The most effective dummies were those with two laterally arranged eyelike spots. The possible role of species-specific key stimuli in avoidance learning and organizing defensive behavior of the paradise fish is discussed.
\end{abstract}

In a previous study on predator recognition in paradise fish (Csányi, 1985), it was found that live fish from another species, whether predatory or harmless in nature, elicit vigorous approach behavior on the part of the paradise fish. Repeated encounters with the same species lead to habituation. If the first encounter resulted in an attack by the predator, the paradise fish fled immediately and in subsequent meetings with the same predator they demonstrated "avoidance" behavior independently of the actions of the predator. Avoidance behavior was also elicited by the harmless goldfish if the paradise fish had previously been given a mild electric shock in the presence of the goldfish. It was concluded that predator recognition was achieved by the paradise fish through a learning process that was based upon fear elicitation in the presence of fish of another species. This finding is in agreement with observations of other prey animals which usually respond to a live or model predator by approach and mobbing or by various types of avoidance behavior (Coss, 1978a, 1978b; Hinde, 1954; Kruuk, 1964).

Although, in most cases, predator recognition has been found not to require experience (Hirsch \& Bolles, 1980), the role for learning has also been shown (Curio, Ernst, \& Vieth, 1978; Kruuk, 1976). In the present studies, I wanted to investigate the characteristic features of predators that elicit approach and, upon attack, flight. Quite plausible features to be considered were the eyes, since eyespot patterns have been well established as feareliciting stimuli in a wide range of prey animals, namely

The author is very grateful to $\mathbf{P}$. J. B. Slater for his valuable comments on earlier drafts of this manuscript. Thanks are also extended to Gy. Kampis for his help in the statistical analysis. The author's mailing address is: Department of Behavior Genetics, L. Eötvös University of Budapest, Jávorka S. u. 14, Göd, H-2131 Hungary. in birds (Blest, 1957; Jones, 1980), mammals (Coss, 1978a), and fish (Coss, 1979).

To examine the possible role of eyespot patterns in predator recognition by the paradise fish, we used various dummies and live goldfish. We chose a typical passive avoidance conditioning situation to test the effects of predatory features. This technique allowed for exact control of the experimental parameters.

\section{GENERAL METHODS}

\section{Subjects}

The subjects were 528 female Macropodus opercularis, $F_{1}$ hybrids of two inbred strains designated as strains $\mathrm{S}$ and $\mathrm{U}$. These fish were bred in our laboratory. All the fish were between 120 and 180 days old at the time of the experiment and were housed in individual $30 \times 15 \times 15 \mathrm{~cm}$ aquaria. The aquaria were well filtered, temperature $\left(28^{\circ} \mathrm{C}\right)$ was held constant, and each unit contained one piece of water plant (Hygrophila polysperma). The animals were fed daily on Tubifex worms.

\section{Apparatus}

Two identical $40 \times 20 \times 20 \mathrm{~cm}$ shuttle-tanks were used (Figure 1). The tanks were separated into two compartments by a green plastic wall, which contained a 3-cm-diam circular gate in the middle. The inner walls of the dark compartment were covered with a mixture of fine-grain sand and silicon rubber. Two stainless steel grids covered the whole walls of the two parallel sides. This compartment was covered by a black-painted lid. The bottom of the light compartment was also covered with silicon and sand, but the side walls were transparent. The lighting in the apparatus was measured at 30 and $200 \mathrm{~lx}$ in the dark and the light sides, respectively.

Shuttling activity was monitored by an infrared photoelectric device located in the gate. This device also served as a trigger for a train of electric shock pulses if the fish entered the dark compartment (20-msec trains of $500 \mathrm{~Hz}$ ac, 50 - to 100-mA shocks every $.2 \mathrm{sec}$, with the first train being given immediately after the fish entered the compartment. When the fish moved out of the dark compartment, the shocks ceased automatically. The parameters of the shuttling activity, such as the latency of the first crossing through the gate - that is, the time from entry into the tank to entry through 


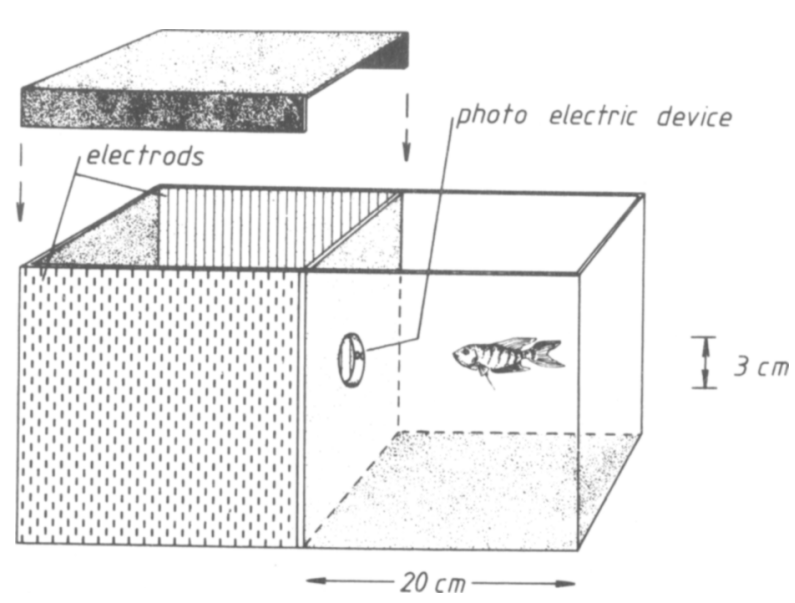

Figure 1. Shuttle-tank used in the passive avoidance experiments.

the gate-into the dark side, the number of crossings and the total amount of time spent in the dark compartment during a 15-min trial were recorded automatically.

After every 5 animals were tested, the water was replaced in the shuttle-tank. Both tanks were placed into a $100 \times 100 \times 100 \mathrm{~cm}$ deep enclosure that was covered by green plastic on five sides. Through the open side of the enclosure, the movement of the fish could be observed by the experimenter sitting behind a green plastic screen. The enclosure was illuminated by six white fluorescent tubes $(20 \mathrm{~W})$ from above.

\section{Procedure}

Forty-eight hours prior to training, all the fish were placed in individual aquaria. During the training sessions, which were conducted twice a day, each fish was placed, using a small hand-net, into the transparent compartment of the shuttle-tank, where it received various treatments. Fifteen minutes later, the fish was removed from the apparatus and returned to its home tank. All training experiments were carried out between 9:00 a.m. and 4:00 p.m. On the first trial, some fish (about $10 \%$ ) did not enter the dark compartment during the $15 \mathrm{~min}$ allowed. In these cases, a small net was used to gently compel the fish to swim through the gate; after $1 \mathrm{~min}$, the fish was removed from the apparatus.

Three different training experiments were carried out. In each experiment, the first four trials were allowed for habituation, during which neither an electic shock nor manipulations with various dummies were applied. Further procedures are given in the descriptions of the experiments.

In the statistical analysis, the latency assigned to fish that remained in the transparent compartment during the whole trial was $900 \mathrm{sec}$.

\section{EXPERIMENT 1}

\section{Method}

Eighty fish were divided into four equal groups. Three of these groups were trained to avoid the dark compartment by being shocked from Trial 5 onward whenever they entered the dark. The shock intensities were 50,75 , and $100 \mathrm{~mA}$. The fourth group served as a no-shock control.

\section{Results}

The effect of habituation during Trials 1-4 was analyzed by a two-way ANOVA with repeated measures (treatment $\times$ trials). There was a marked reduction of latency in subsequent trials $[\mathrm{F}(3,76)=61.0, \mathrm{p}<.001]$.
The amount of time spent in the dark increased considerably during habituation $[\mathrm{F}(3,76)=106.9, \mathrm{p}<.001]$. The number of crossings also increased significantly $[F(3,76)=28.8, p<.001]$. There were no significant differences among the groups in treatments $[F(3,76)=$ $1.1, F(3,76)=0.87, F(3,76)=1.05$, for latency, time spent in the dark, and number of crossings, respectively] or interactions $[\mathrm{F}(9,228)=0.47, \mathrm{~F}(9,228)=1.51$, $F(9,228)=0.74$, for latency, time spent in the dark, and for the number of crossings, respectively]. Therefore, the data of the various groups on Trials 1-4 were combined in Figures 2-4.

Punishment by shock reversed the direction of changes in all three parameters. During the shock trials (Trials 5-8, Figures 2, 3, and 4), latency increased and the time spent in the dark and the number of crossings decreased. The effect of shock among Trials 5-8 was analyzed by a two-way ANOVA with repeated measures (treatment $\times$ trials). The changes were significant in all three parameters [latency-F(3,76) $=90.2, \mathrm{p}<.001$, $\mathrm{F}(3,228)=65.8, \mathrm{p}<.001, \mathrm{~F}(9,228)=18.8$, $\mathrm{p}<.001$; time spent in the dark- $\mathrm{F}(3,76)=97.6$, $\mathrm{p}<.001, \mathrm{~F}(3,228)=7.1, \mathrm{p}<.01, \mathrm{~F}(9,228)=1.86$, n.s.; number of crossings- $\mathrm{F}(3,76)=32.96, \mathrm{p}<.001$, $\mathrm{F}(3,228)=3.05, \mathrm{p}<.05, \mathrm{~F}(9,228)=0.41$, n.s.; for latency, trials, and the interaction in each case]. Group data obtained in Trials 5-8 were compared across treatment effects using the Duncan multiple range test with the between-groups error MS term of the overall ANOVA. Two significantly different $(p<.01)$, nonoverlapping ranges containing the 100 - and $75-\mathrm{mA}$ groups and the $50-\mathrm{mA}$ and control groups were found for latency and number of crossings. In the case of time spent in the dark, there were three significantly different ranges: (1) the control group, (2) the 50-mA group, and (3) the 75- and 100$\mathrm{mA}$ groups.

Analysis of Shock Trials 6-8 revealed considerable differences in the character of the three measured parameters. Only the effect of treatment was significant

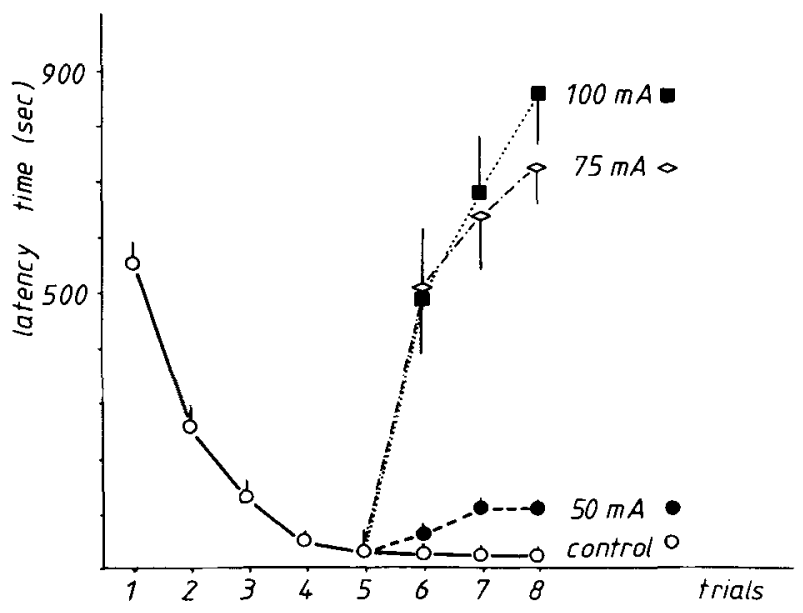

Figure 2. Increases in latency during various shock treatments. Group means \pm SE are shown. 


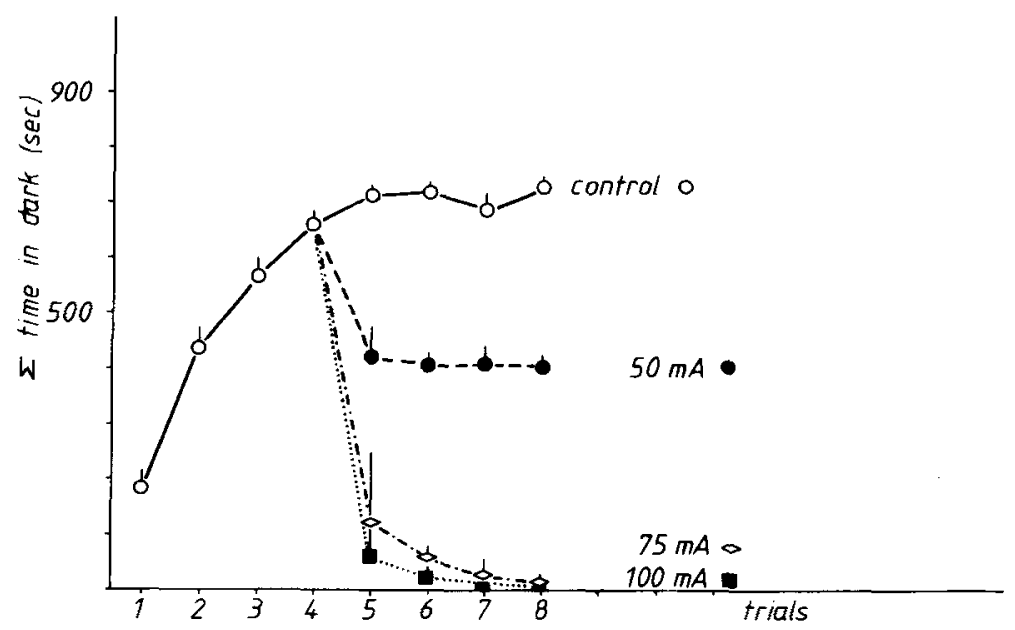

Figure 3. Total time spent in the dark during various treatments. Group means $\pm \mathrm{SE}$ are shown.

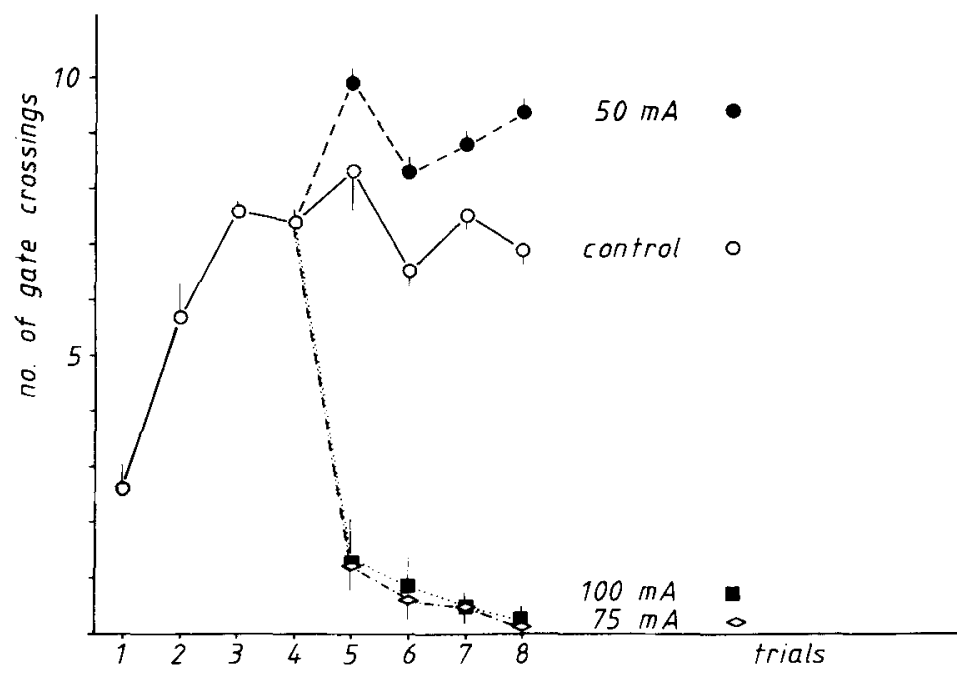

Figure 4. The number of gate crossings during various treatments. Group means $\pm \mathrm{SE}$ are shown.

in both number of crossings and time spent in the dark [number of crossings $-\mathrm{F}(3,76)=30.65, \mathrm{p}<.001$, $\mathrm{F}(2,152)=0.03$, n.s., $\mathrm{F}(2,152)=0.53$, n.s.; time spent in the dark- $\mathrm{F}(3,76)=98.8, \mathrm{p}<.001, \mathrm{~F}(2,152)=2.6$, n.s., $F(6,152)=1.2$, n.s.; for treatment, trials, and the interaction, respectively, in each case]. Contrary to these findings, postshock changes in latency were significant not only for treatment shock intensity but for trials and the interaction as well $[\mathrm{F}(3,76)=92.2, \mathrm{p}<.001$, $\mathrm{F}(2,152)=11.63, \mathrm{p}<.001, \mathrm{~F}(6,152)=3.02$, $\mathrm{p}<.001$, for treatment, trials, and the interaction, respectively].

\section{Discussion}

Active avoidance conditioning is the most frequently used technique for studying learning in small rodents, such as mice and rats, and also in other species, such as toads
(Karplus, Algon, \& Samuel, 1980) and goldfish (Pinckney, 1967; Woodard \& Bitterman, 1971; Zerbolio \& Wickstra, 1979). It has even been used on Macropodus opercularis (Brookshire \& Hognander, 1968). For our purpose, because of problems caused by the intended use of the various dummies, a passive avoidance paradigm seemed better. In an active avoidance design, the dummy should also be shuttled between the compartments of the experimental chamber, but this creates technical problems.

The aim of Experiment 1 was to investigate some parameters of the learning process in paradise fish in order to design the experiments using various dummies. The parameters examined were latency, number of crossings, and amount of time spent in the dark.

The three measures revealed different aspects of the behavior of the paradise fish in the present learning situation. Latency showed a marked increase in groups treated 
with 75- or 100-mA shock (Figure 2). This was the only parameter that increased significantly day after day in the above groups, as revealed by the analysis of the postshock trials. Therefore, it can be assumed that an avoidance learning process was expressed most clearly in the latency parameter.

With shock in the dark compartment, the fish showed escape behavior, but the total time spent in the dark changed only during the first shock trial (Figure 3), correlating roughly with shock intensity. Therefore, it is reasonable to suppose that this parameter reflects the degree of discomfort in the shock compartment. It is also worth noting that the group shocked with $50 \mathrm{~mA}$ had no significant increase in latency, but that the total time spent in the dark fell to about $55 \%$ of that of the control group, and this difference was significant.

The third parameter, the number of crossings, also did not show significant changes with the second shock trial, and the mean values in the control and $50-\mathrm{mA}$ groups were very similar, just as they were in the latency measure. Lester $(1967,1968)$ observed that a mild increase in the fear level of rats increased their exploratory tendency. Gate crossings can certainly be viewed as a special form of exploration by the paradise fish. This was also supported by other behavioral observations. Before the gate crossings were made, the fish frequently oriented toward the gate and lowered their speed or stopped for a moment in front of the gate. Although mild shock of $50 \mathrm{~mA}$ significantly diminished the amount of time spent in the dark compartment, thus showing the unpleasant nature of shock, it did not change the number of crossings significantly. This appears to be in agreement with the results of Lester's (1968) experiments with rats.

Our conclusions from Experiment 1 are that a mild, 50$\mathrm{mA}$ shock in this passive avoidance situation, while being clearly unpleasant, maintains exploration and does not initiate observable learning. High-level shock promotes escape behavior, facilitates learning (expressed in increases in latency to enter the dark chamber), and inhibits exploration, in agreement with the findings of similar studies using other animals.

\section{EXPERIMENT 2}

In Experiment 2, the effects of a mild shock ( $50 \mathrm{~mA})$ and of the presence of various dummies and of live goldfish from Trial 5 onward were examined.

\section{Method}

After the four habituation trials, 408 fish were divided into 10 groups of various sizes, and from Trial 5 onward these groups were treated differently. In some treatments, various dummies were placed in the back part of the dark compartment. The simplest of the dummies was a small red-light lamp (LED), $4 \mathrm{~mm}$ in diameter, mounted on a piece of Plexiglas connected to a small strip of lead so that it stood firmly on the bottom (dummy A; Figure 5). Next in the series were two similar red lamps arranged either vertically (dummy B) or horizontally (dummy C). A more fish-like dummy was made from the head of a plastic toy fish, with two small red lamps substituted for the eyes (dummy D). The last "dummy" was a live adult goldfish, $10 \mathrm{~cm}$ long and large enough not to be able to leave the dark compartment through the gate. The different dummies and $50-\mathrm{mA}$ shock were introduced in Trial 5 as follows:

Groups 1-3 were not shocked. For Group $1(n=20)$, no dummy was introduced. Group $2(n=18)$ had the goldfish, and Group 3 $(\mathrm{n}=41)$ had dummy D. Groups $4-10$ were shocked by $50 \mathrm{~mA}$. For Group $4(n=79)$, no dummy was used. Group $5(n=20)$ had dummy $D$ without its lamps being turned on- $D_{0}$. Group $6(n=21)$ had dummy A; Group $7(n=50)$, dummy B; Group $8(n=52)$, dummy $C$; and Group $9(n=71)$, dummy D. Group $10(n=36)$ had the goldfish.

\section{Results}

To compare the effects of the various dummies, the group means of various behavior parameters were calculated from the individual averages of the last three trials, Trials 6-8, since the last three postshock trials seemed to provide the most reliable part of the individual learning curves. These averages are good indicators of the animal's avoidance learning (latency, Figure 6), its readiness to escape (time spent in the dark, Figure 7), and its tendency to explore (number of crossings, Figure 8).

Avoidance learning, indicated by high latency, showed a tendency to increase in groups shocked in the presence of dummies B, C, and D and the live goldfish.

Statistical analysis of the latencies by one-way ANOVA for all 10 groups was highly significant $[F(9,398)=27.7$,
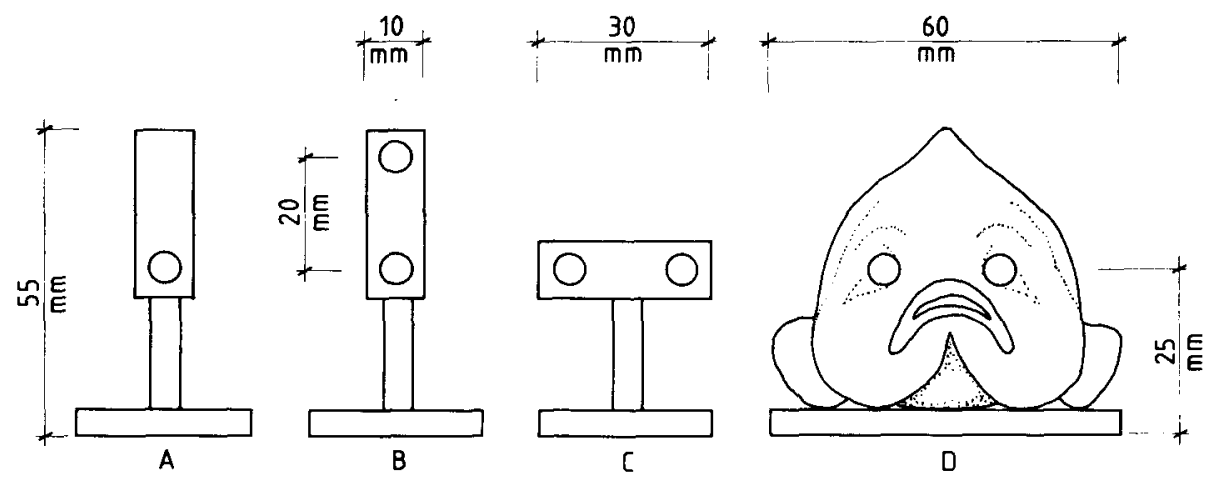

Figure 5. Various dummies used in the passive avoidance experiments. 
$\mathrm{p}<.001]$. Post hoc comparisons of the means by Duncan range test $(p<.05)$ revealed four different, partially overlapping ranges, which are shown in Figure 6.

Total time spent in the dark also changed in the presence of some dummies. The one-way ANOVA for all 10 groups was significant $[\mathrm{F}(9,398)=18.44, \mathrm{p}<.001]$ Four nonsignificant ranges $(p<.05)$ were found by the Duncan multiple range test. These are shown in Figure 7.

Exploration reflected in the number of crossings was also affected by the dummies. A one-way ANOVA for

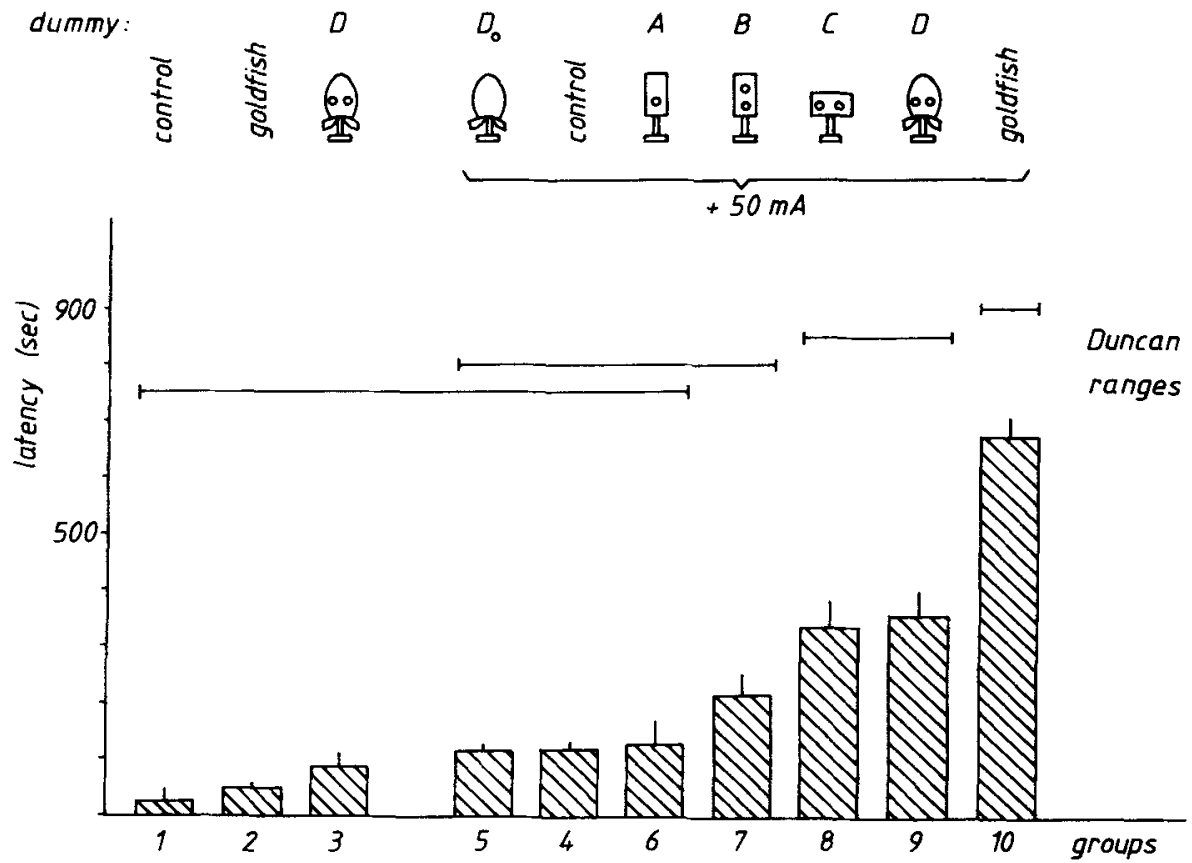

Figure 6. Increase in latency in groups treated by various dummies. Bars represent means $\pm \mathrm{SE}$; Duncan ranges are also shown.

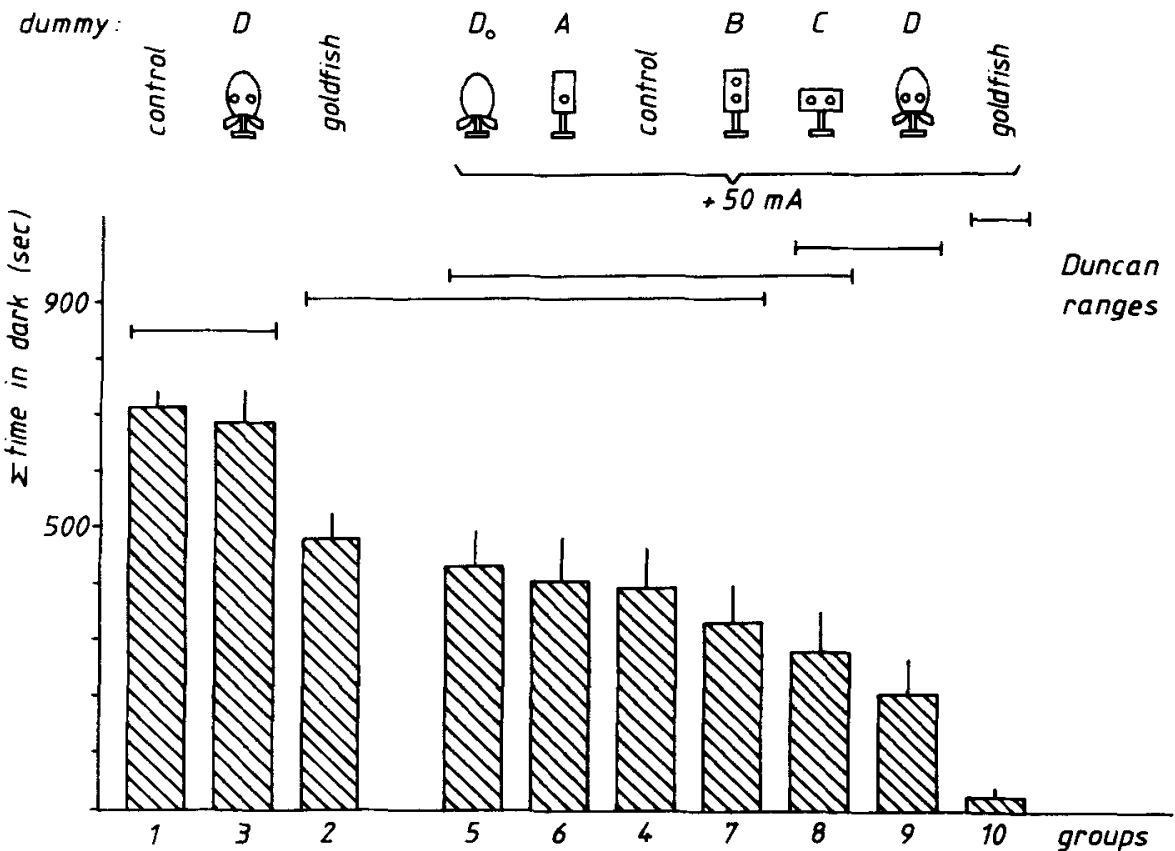

Figure 7. Time spent in the dark by groups exposed to various dummies. Bars represent means $\pm \mathrm{SE}$; Duncan ranges are also shown. 
all groups was highly significant $[\mathrm{F}(9,398)=10.28$, $\mathrm{p}<.001]$. A Duncan range test $(\mathrm{p}<.05)$ revealed the three nonsignificant ranges shown in Figure 8.

Observation of the fishes revealed characteristic differences in overt behavior among the groups. Subjects in the groups treated with both shock and with dummy C, dummy D, or the goldfish (Groups 8, 9, and 10) swam out very quickly from the dark compartment after being shocked and then usually turned back immediately, swam to the gate, and spent considerable time looking into the dark compartment. The fish in the other groups just came out normally and went into the dark again without any hesitation. In the groups treated with both goldfish and shock, the goldfish itself also received the shock and reacted with frequent jumps and rushes. This behavior certainly raised the discomforting features of the dark compartment for the paradise fish.

\section{Discussion}

These results indicate that the presence of fish-like dummies enhances the effect of a mild shock on all three parameters. On latencies, live fish exert the greatest effect (Group 10; Figure 6). Next in effect, after the goldfish, is the most fish-like dummy, D (Group 9), although dummy $\mathrm{C}$ has almost the same effect (Group 8), demonstrating that the most important properties of these dummies are the two lateral eye-like spots provided by the lamps. The effects of dummy $\mathrm{D}_{0}$, without lamps (Group 5), and dummy A, which had only one lamp (Group 6), were not significantly different from that of the control. Thus, two lateral eyespots certainly have a key-stimulus character. Even the configuration of the two spots seems to be important, since the horizontal arrange- ment (Group 8) is significantly better at raising latency than is the vertical one (Group 7). This finding is certainly not unique: It is well known that eyespots induce avoidance behavior in certain small mammals (Coss, 1978b), birds (Blest, 1957; Jones, 1980), and fish (Coss, 1979).

As Experiment 1 showed, total time in the dark reflected readiness to escape as a result of the discomfort of the treatments. Experiment 2 seemed to show that dummy D without shock (Group 3) exerted no unpleasant effect and that a live companion goldfish without shock (Group 2) was almost as uncomfortable as mild shock alone (Group 4). In general these no-shock groups tend not to differ from the no-shock no-dummy control (Group 1). If both shock and dummy D or the goldfish are present (Groups 9 and 10), the discomfort of the treatments is greatly enhanced, as shown by the significant decrease of total time in the dark.

The components of the "discomfort' exerted by the dummies and mild shock are at least of two kinds. The first is clearly the pain caused by the shock, which is independent of the presence or absence of the dummies (Groups 1 and 4), and the other is most probably fear. The influence of the fear component is not observed when the dummies have been presented without shock because the total times in the dark are almost the same for the control and the dummy groups (Groups 1 and 3 ) in this condition. The most plausible explanation is that the dummies do have fear-eliciting properties, but only in the presence of a mild pain. The same can be said for live goldfish (Csányi, 1985).

The effect of the dummies on the number of crossings differs from their effect on the time spent in the dark. The

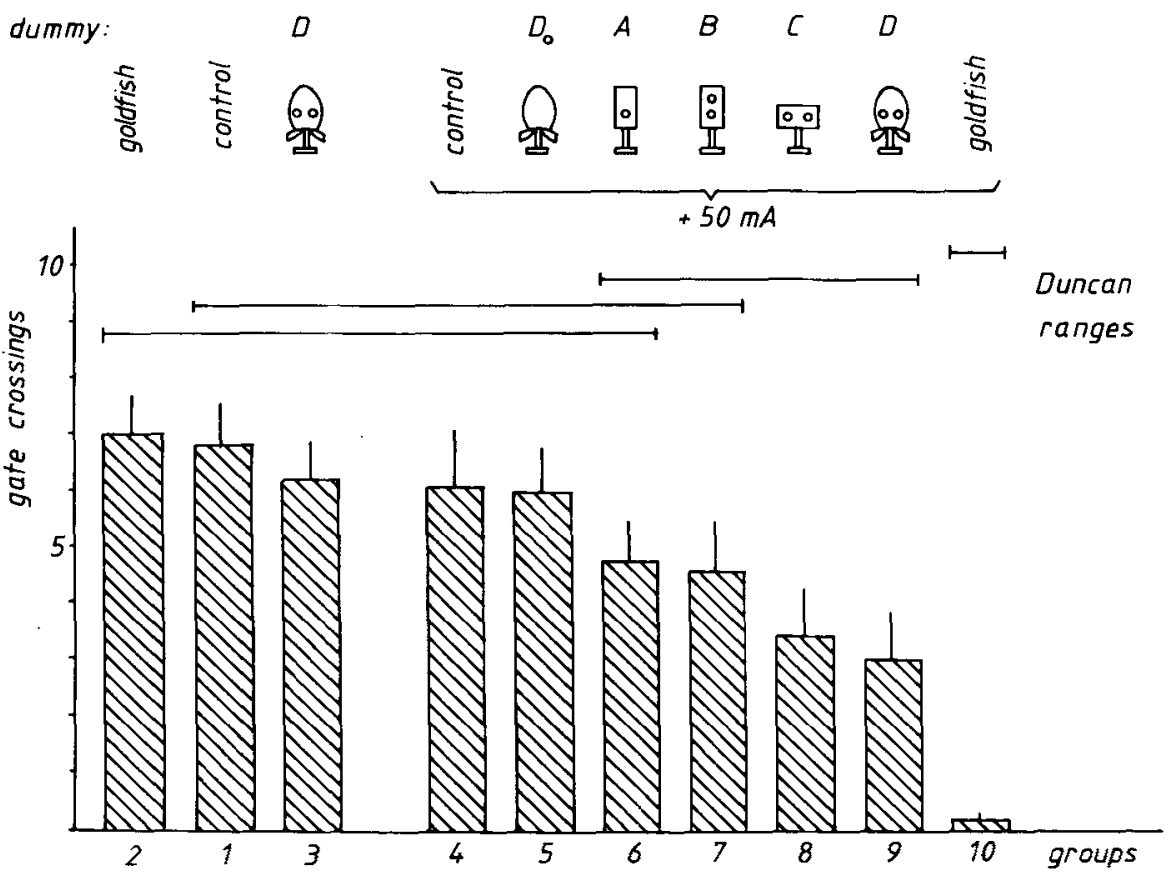

Figure 8. The number of gate crossings in groups exposed to various dummies. Bars represent means $\pm \mathrm{SE}$; Duncan ranges are also shown. 
number of crossings does not differ among the first four groups, two of which (Groups 2 and 4) showed a considerable decrease in total time in the dark, evidencing the discomfort of the treatment. This result supports the assumption that mildly unpleasant treatments maintain exploratory behavior.

\section{EXPERIMENT 3}

The aim of Experiment 3 was to examine the reversibility of the effect of fish-like dummies on the enhancement of latency, the parameter by which learning is seemingly best reflected in this passive avoidance learning situation. Shock of $100 \mathrm{~mA}$ was used, because it was, by itself, effective enough to elicit considerable avoidance behavior in Experiment 1.

\section{Method}

Forty fish were divided into four groups after the habituation trials. Group $1(n=10)$ served as control, with neither shock nor dummies applied. Group $2(n=10)$ was shocked with $100 \mathrm{~mA}$ but had no dummy present. Group $3(n=10)$ had dummy $D$ and was shocked with $100 \mathrm{~mA}$ from Trial 5 through Trial 11; on Trials 12, 13, and 14 , the dummy was removed and the shock was omitted. Group 4 $(n=10)$ was treated like Group 3 , but the dummy was replaced on Trial 14

\section{Results and Discussion}

The results are shown in Figure 9. Treatment with 100$\mathrm{mA}$ shock alone and 100-mA shock with dummy D quickly enhanced the latency, and there was no significant difference between the two treatments. Latency decreased considerably when both the dummy was removed and the shock was omitted (Groups 3 and 4 on
Trials 12-14 and 12-13, respectively). Latency increased again when the dummy was placed back but shock continued to be omitted (Group 4, Trial 14).

The effect of the dummy removal was significant, as revealed by an ANOVA. Trials 12-14 were compared by two-way ANOVA with repeated measures (treatment $x$ trials) for all groups and separately for the shocked groups (Groups 2, 3, and 4). The differences were highly significant [treatments, $F(3,36)=67.5, p<.001$, and $\mathrm{F}(2,27)=35.9, \mathrm{p}<.001 ;$ trials, $\mathrm{F}(2,72)=6.68$, $\mathrm{p}<.01$, and $\mathrm{F}(2,54)=6.67, \mathrm{p}<.01$; interactions, $F(6,72)=13.23, p<.001$, and $F(4,54)=14.15$, $p<.001]$. Some pairwise comparisons were also made. Differences were significant for treatment between Groups 2 and $3[F(1,18)=72.6, p<.001, F(2,36)=$ 2.68 , n.s., and $F(2,36)=2.68$, n.s., for treatment, trials, and interaction, respectively]. In a comparison of Group 3 and Group 4, differences in all three parameters were significant $[\mathrm{F}(1,18)=5.83, \mathrm{p}<.05, \mathrm{~F}(2,36)=6.65$, $\mathrm{p}<.01, \mathrm{~F}(2,36)=16.6, \mathrm{p}<.001$, for treatment, trials, and interaction, respectively]. For Trial 14, Groups 3 and 4 were compared by one-way ANOVA. The difference was significant $[F(1,18)=115.4, p<.001]$.

This experiment supports the assumption that, with a fish-like dummy present, the painful experience of the shock was associated by the subjects with the dummy. Without the dummy, it was the physical cues of the dark compartment that exerted a long-lasting effect on behavior. Fish belonging to the latter group completely avoided the dark compartment on the last five trials. The effect of the dummy in this experiment can also be explained by the notion of an overshadowing of contextual stimuli by a more salient, biologically relevant stimulus (Rescorla, 1968; Wagner, 1969).

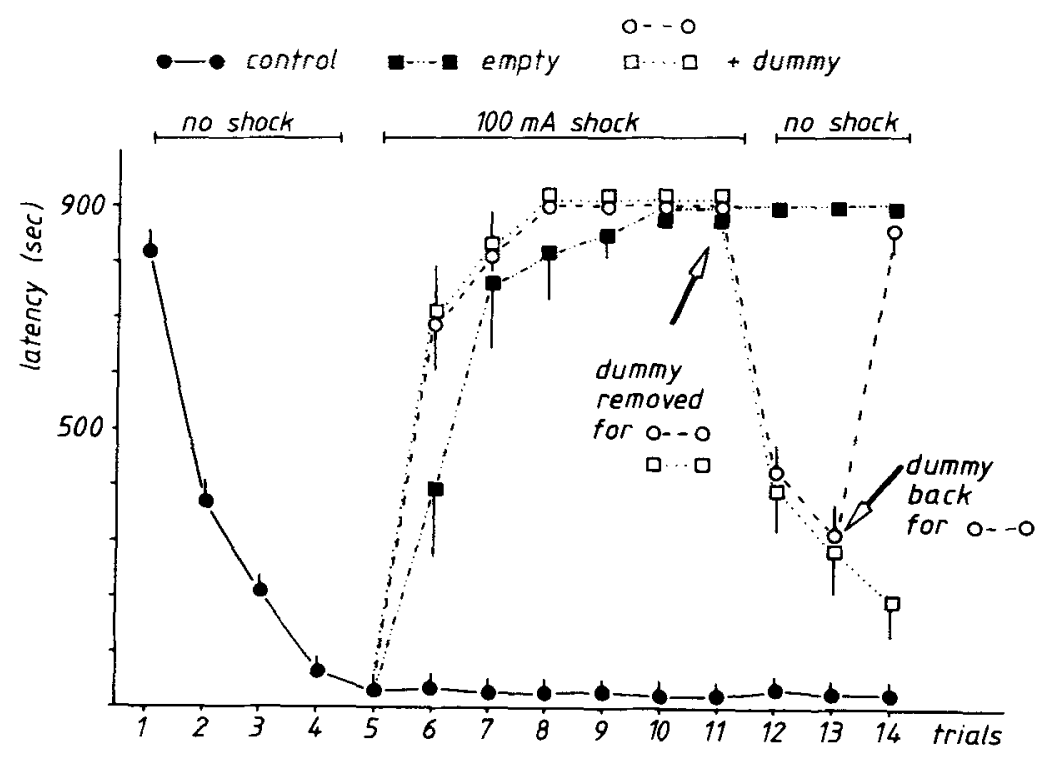

Figure 9. Latency time during manipulation with dummies. Arrows point to the trials that were followed by removal and replacement of the dummy in the respective groups. Means $\pm \mathrm{SE}$ are shown. 


\section{GENERAL DISCUSSION}

Various psychological schuols have invested enormous effort in the search for a general theory of learning. Although this line of investigation has revealed a great many facets of the animal learning process and has led to the discovery of very effective training methods, the theories and beliefs underlying the generalized psychological approach has been seriously questioned during the last 20 years by researchers who started to emphasize the various constraints of instrumental and classical conditioning (Garcia \& Koelling, 1966; Rozin \& Kalat, 1972; Seligman, 1970; Seligman \& Hager, 1972). The bulk of the evidence in favor of the biological boundaries approach has been provided by taste-aversion learning, but studies of other forms of learning, such as instrumental avoidance in rats (Bolles, 1970) and complementary data using food reinforcement in an operant conditioning paradigm with hamsters (Shettleworth, 1972) also showed species-specific "biological constraints" on the animal's learning ability. The discovery of the constraints-onlearning phenomena successfully undermined the principle of equipotentiality, which, although it had never been explicitly believed, greatly influenced the thinking of students in this field. The other pinnacle of the psychological theory, namely the view that all instances of associative learning involve the same basic underlying process, was very little challenged by the constraints-on-learning phenomena (Roper, 1983). A few researchers, rather than abandoning the search for general laws of learning, responded by attempting to formulate somewhat restricted new "laws" to accommodate the phenomena of learning constraints (Revusky, 1977), or tried to integrate the species-specific instances of learning into the traditional framework of the psychological theory on the basis of a general process approach (Domjan \& Galef, 1983). In my opinion, the crucial problem is not whether the instances of associative learning involve the same underlying process, or even the validity of the principle of equipotentiality, but the specific relationships of the associative process(es) to the given species-specific behavioral system, the importance of which unfortunately has not been recognized by the general process approach.

Learning may be viewed as a special means of adaptation, an ability evolved by animals in the course of evolution, which can be properly studied only by considering the close and dynamic relationship between the behavior repertoire of a given species and its environment (Johnston, 1981, 1982). The various forms of learning may be considered as parts of the ethogram in the same way as the genetically better defined, less flexible behavior patterns.

The most ethologically oriented theory of aversive conditioning was constructed by Bolles (Bolles, 1970; Bolles \& Fanselow, 1980). The principal claims of this theory are the following: Any stimulus that causes fear elicits species-specific defense reactions (SSDR) unconditionally. If the unconditioned stimulus is accompanied by a contiguous, neutral stimulus, then, after some repetition, the conditioned stimulus alone is capable of eliciting the SSDR. And avoidance learning could occur rapidly only if the required response was one of the animal's SSDRs.

If we apply this simple model to the case of passive avoidance conditioning in the paradise fish, it fits the observations only very roughly. High-intensity shock elicits specific escape reactions in the paradise fish, and, if the experience is repeated, the features of the place where the shock occurred are enough to activate the passive avoidance response. The design of the apparatus used in this experiment was appropriate for the study of the avoidance reaction, measured as the increase in latency, that is, the escape reactions reflected in time spent in the dark. Besides some agreement with Bolles's model, there are two important features of the behavior of paradise fish which suggest the need for considerable modification of the model. If the animal is shocked by a relatively mild, but clearly unpleasant, shock, it maintains exploration, and this is generally not included among SSDRs. Such exploratory behavior in these experiments was indicated by the large number of gate crossings.

Our previous observations of the interactions of paradise fish and a live predator (Csányi, 1985) also showed that a naive paradise fish or one raised in isolation reacts to the sight of a predator by active exploration. A shock of high intensity or an attack by the predator lowers this tendency to explore.

The second important feature of these experiments was that the presence of eyespot-like stimuli greatly influenced the exploratory behavior of paradise fish treated by mild electric shocks. Although a mild shock was ineffective if applied alone, mild shock and an eyespot model together led to avoidance conditioning. Any simple explanation by sensitization was ruled out because the stimuli were highly specific. Besides live fish, only two laterally arranged spots were suitable for avoidance conditioning (Experiment 2), and avoidance was maintained by the presence of the appropriate stimuli even if shock level was high enough to elicit avoidance alone (Experiment 3 ). These results are very similar to previous ones (Csányi, 1985) that showed that a harmless goldfish can be turned into an object that is actively avoided by the paradise fish when a mild shock is applied to the paradise fish in the goldfish's presence.

To account for the main features of the paradise fish's learning, Bolles's model must be supplied with a new feature. This new feature is the species-specific key-stimulus (SSKS). Upon the appearance of such stimuli in the environment of the paradise fish, an identification process starts and results in immediate orientation and thorough exploration.

If the carrier of the key stimuli is passive, then the exploratory behavior slowly diminishes by way of habituation. If the carrier of the SSKS interacts with the paradise fish and causes fear or pain, then the SSDR becomes activated and the exact features of the carrier become fixed in memory by S-S-type associations. If the same stimuli recur, then the SSDR becomes elicited by its representation in memory without the need for exploration. 
Bolles and Fanselow (1980), in their description of avoidance conditioning, placed emphasis on the role of fear as the main organizer of behavior in the learning situation. Our experiments supplement this conception by suggesting an important organizational role for SSKSs. SSKSs direct the association process: they signal which objects in the environment are worth thorough exploration and which features must be associated with the concurrently occurring pain or fear. In a new environment, the animal is continuously searching for the appropriate SSKSs that are the organizational focal point of its defensive behavior.

An important function of the animal's brain is the dynamic representation of its environment with which it can predict events relevant to its survival. It can be safely assumed that the brain of the paradise fish has a genetically determined predisposition in the form of a crude "mental template," which directs exploration of the environment and, upon encounters with SSKS carriers, renders identification possible. In the natural environment, where both harmless and predatory carriers of SSKS can be found, encounters with predators may result in chase or painful injury, which initiates a learning process that results in a representation, in the paradise fish's brain, of the actual features of a given predator. This representation acts as an organizer of behavior in subsequent encounters.

The paradise fish lives in small ponds and streams, where the numbers of the possible predator species are certainly under some limits. Occasional meeting with one of them results in an SSKS-directed learning process which, throughout the entire life of the animal, creates a network of the representation of the appropriate predator. This very network can be regarded as a dynamic model of the given environment. The dynamics of this model results in avoidance behavior by the paradise fish if, and only if, it is necessary-that is, only in the case of the appearance of the predator. The ability to rely on this model certainly fulfills the criteria of the ability to predict.

\section{REFERENCES}

BLEsT, A. D. (1957). The function of eyespot patterns in the Lepidoptera. Behaviour, 11, 209-256.

BOLLES, R. C. (1970). Species-specific defense reactions and avoidance learning. Psychological Review, 77, 32-48.

Bolles, R. C., \& Fanselow, M. S. (1980). A perceptual-defensiverecuperative model of fear and pain. Behavioral \& Brain Sciences, 3, 291-323.

Brookshire, K. H., \& Hognander, O. C. (1968). Conditioned fear in the fish. Psychological Reports, 22, 78-81.

Coss, R. G. (1978a). Development of face aversion by the jewel fish. Zeitschriff für Tierpsychologie, 48, 28-46.

Coss, R. G. (1978b). Perceptual determinations of gaze aversion by the lesser mouse lemur, Microcebus murimus: The role of two facing eyes. Behaviour, 64, 248-270.

Coss, R. G. (1979). Delayed plasiticity of an instinct: Recognition and avoidance of two facing eyes by the jewel fish. Developmental Psychobiology, 12, 335-345.
CSÁNYI, V. (1985). Ethological analysis of predator avoidance by the paradise fish, Macropodus opercularis L: I. Predator recognition. Behaviour, 92, 227-240.

CURIo, E. K., ERNST, K., \& VIETH, W. (1978). The adaptive significance of avia mobbing II. Cultural transmission of enemy recognition in blackbirds: Effectiveness and some constraints. Zeitschrift für Tierpsychologie, 48, 184-202.

Domjan, M., \& Galef, B. G., JR. (1983). Biological constraints on instrumental and classical conditioning: Retrospect and prospect. Animal Learning \& Behavior, 11, 151-162.

Garcia, J., \& KoElling, R. A. (1966). Relation of cue to consequence in avoidance learning. Psychonomic Science, 4, 123-124.

Hinde, R. A. (1954). Factors governing the changes in strength of a partially inborn response, as shown by the mobbing behaviour of the chaffinch (Fringilla coelebs): I. The nature of the response and the examination of its course. Proceedings of the Royal Society $B, 142$, 306-331.

HIRSCH, S. M., \& Bolles, R. C. (1980). On the ability of prey to recognize predators. Zeitschrift für Tierpsychologie, 54, 71-84.

JoHNSTON, T. D. (1981). Contrasting approaches to a theory of learning. Behavioral \& Brain Sciences, 4, 125-173.

JoHNSTON, T. D. (1982). Selective cost and benefits in the evolution of learning. Advances in the Study of Behavior, 12, 65-106.

JONES, R. B. (1980). Reactions of male domestic chicks to twodimensional eye-like shapes. Animal Behaviour, 28, 212-218.

Karplus, I., Algon, D., \& Samuel, O. (1980). Acquisition and retention of dark avoidance by the toad Xenopus laevis. Animal Learning \& Behavior, 9, 45-56.

Kruuk, H. (1964). Predators and anti-predator behaviour of the blackheaded gull (Larus ridibundus). Behaviour, 11(Suppl.), 129.

KRUUK, H. (1964). Predators and anti-predator behaviour of the blackheaded gull (Larus ridibundus). Behaviour, Suppl. 11, 1-129.

LESTER, D. (1967). Sex differences in exploration: Toward a theory of exploration. Psychological Record, 17, 55-62.

LESTER, D. (1968). Two tests of a fear motivated theory of exploration. Psychonomic Science, 10, 385-386.

PINCKNEY, G. A. (1967). Avoidance learning in fish as a function of prior fear conditioning. Psychological Reports, 20, 71-74.

Rescorla, R. A. (1968). Probability of shock in the presence and absence of CS in fear conditioning. Journal of Comparative \& Physiological Psychology, 66, 1-5.

ReVUSKY, S. (1977). Learning as a general process with an emphasis on data from feeding experiments. In N. W. Milgram, L. Krames, \& T. M. Alloway (Eds.), Food aversion learning (pp. 1-51). New York: Plenum Press.

Roper, T. J. (1983). Learning as a biological phenomenon. In T. R. Halliday \& P. J. B. Slater (Eds.), Animal behaviour (pp. 178-213). Oxford: Blackwell.

Rozin, P., \& Kalat, J. W. (1972). Learning as a situation specific adaptation. In M. E. P. Seligman \& J. L. Hager, (Eds.), Biological boundaries of learning (pp. 66-96). New York: Appleton-CenturyCrofts.

Seligman, M. E. P. (1970). On the generality of the laws of learning. Psychological Review, 77, 406-418.

Seligman, M. E. P., \& Hager, J. L. (Eds.) (1972). Biological boundaries of learning. New York: Appleton-Century-Crofts.

SHETTLEWORTH, S. J. (1972). Constraints on learning. Advances in the Study of Behavior, 4, 1-68.

WAGNER, A. R. (1969). Stimulus selection and a modified continuity theory. In G. H. Bower \& J. T. Spence (Eds.), The psychology of learning and motivation (Vol. 3, pp. 1-43). New York: Academic Press.

Woodard, W. T., \& Bitterman, M. E. (1971). Classical conditioning of goldfish in the shuttlebox. Behavior Research Methods \& Instrumentation, 3, 193-194.

Zerbolio, D. J., \& WICKSTRA, L. L. (1979). Instrumentally based conditioned avoidance response acquisition in goldfish in a simultaneous presentation task. Bulletin of the Psychonomic Society, 13, 311-313.

(Manuscript received December 10, 1984; revision accepted for publication May 20, 1985.) 